\title{
Regulation of Glucose Transport in Candida utilis
}

\author{
By J. M. PEINADO, ${ }^{1 *}$ P. J. CAMEIRA-DOS-SANTOS ${ }^{2} \dagger$ AND \\ M. C. LOUREIRO-DÍAS ${ }^{2}$ \\ ${ }^{1}$ Departamento de Microbiología, Facultad de Farmacia, Universidad Complutense, \\ 28040 Madrid, Spain \\ ${ }^{2}$ Laboratorio de Microbiología, Gulbenkian Institute of Science, 2781 Oeiras, Portugal
}

(Received 24 March 1988; revised 9 June 1988; accepted 5 September 1988)

\begin{abstract}
The transport systems for glucose present in Candida utilis cells, growing in batch and continuous cultures on several carbon sources, have been studied. Two different systems were found: a proton symport and a facilitated diffusion system. The high-affinity symport $\left(K_{\mathrm{m}}\right.$ for glucose about $15 \mu \mathrm{M}$ ) transported one proton per mole of glucose and was partially constitutive, appearing in cells grown on gluconeogenic substrates such as lactate, ethanol and glycerol. It was also induced by glucose concentrations up to $0.7 \mathrm{~mm}$ and repressed by higher ones. The level of repression depended on the external glucose concentration at which cells had grown in a way similar to that shown by the maltose-uptake system, so both systems seem to be under a common glucose control. Initial uptake by facilitated diffusion, the only transport system present in cells growing at glucose concentrations higher than $10 \mathrm{mM}$, showed a complex kinetic dependence on the extracellular glucose concentration. This could be explained either by the presence of at least two different systems simultaneously active, one with a $K_{\mathrm{m}}$ around $2 \mathrm{~mm}$ and the other with a $K_{\mathrm{m}}$ of about $1 \mathrm{M}$, or by the allosteric or hysteretic behaviour of a single carrier whose apparent $K_{\mathrm{m}}$ would oscillate between 2 and $70 \mathrm{~mm}$.
\end{abstract}

\section{INTRODUCTION}

Several systems have been described for glucose transport in yeasts. In Saccharomyces cerevisiae a facilitated diffusion was reported many years ago (for a review see Eddy, 1982), and the first glucose- $\mathrm{H}^{+}$symport was described in Rhodotorula gracilis by Hofer \& Misra (1978). In recent years both types of system have been found in some other yeasts (Spencer-Martins \& van Uden, 1985; Loureiro-Días, 1987). For Candida utilis, a repressible $\mathrm{H}^{+}$symport was found in cells grown on lactate or under glucose limitation in the chemostat (Eddy \& Hopkins, 1985). Postma et al. (1987) reported that glucose was transported with different affinities by cells grown at different growth rates in a glucose-limited chemostat.

In the present work we have studied the nature and regulation of the transport systems for glucose that appear in $C$. utilis cells grown under different conditions.

\section{METHODS}

Organism and culture conditions. The organism used was Candida utilis IGC3092 (CBS 890). It was maintained in slant cultures with YPG agar (yeast extract $5 \mathrm{~g} \mathrm{I}^{-1}$; peptone $1 \mathrm{~g} \mathrm{I}^{-1}$; glucose $2 \mathrm{~g} \mathrm{I}^{-1}$ and agar $2 \mathrm{~g} \mathrm{I}^{-1}$ ), and was grown in the synthetic medium described by van Uden (1967), with sugars as indicated in the text.

For continuous culture experiments, we used a Bioflo C30 fermenter (New Brunswick, NJ, USA) with a working volume of $750 \mathrm{ml}$. The temperature was $28^{\circ} \mathrm{C}$; the $\mathrm{pH}$ was maintained at 4.0 by the addition of $1 \mathrm{M}-\mathrm{KOH}$ using a pHstat device (Radiometer). The culture was carbon-limited at all the dilution rates studied, as shown by the constant cell yield obtained: $0.55 \pm 0.042 \mathrm{~g}$ biomass per $\mathrm{g}$ total carbohydrate consumed (mean $\pm \mathrm{SD}$; seven

† Present address: Estaçao Vitivinícola Nacional, Dois Portos, 2575 Runa, Portugal. 
determinations). Steady-state cells were harvested by centrifugation in an Eppendorf centrifuge for $10 \mathrm{~s}$ and washed twice with ice-cold demineralized water.

For batch cultures we used 2-litre shake flasks with $500 \mathrm{ml}$ medium in an orbital incubator at $28^{\circ} \mathrm{C}$. Cells were harvested in the mid-exponential phase $\left(\mathrm{OD}_{640}\right.$ about 0.7$)$ in a $\mathrm{B} 20$ International centrifuge at $4{ }^{\circ} \mathrm{C}$ and washed twice with ice-cold demineralized water.

Final suspensions of cells, from continuous or batch cultures, were prepared in demineralized water at a concentration of $50 \mathrm{mg}$ dry weight $\mathrm{ml}^{-1}$, kept on ice and used for transport measurements within $2 \mathrm{~h}$.

Calculation of the specific consumption rate of glucose, $q_{\mathrm{G}}$. The $q_{\mathrm{G}}$ value for chemostat-grown cells at each steadystate was calculated using the equation $q_{\mathrm{G}}=D\left(S_{0}-S\right) / X$, where $D$ is the dilution rate, $S_{0}$ and $S$ are the concentrations of glucose in the fresh medium and in the fermenter respectively, and $X$ is the biomass concentration in the fermenter.

Measurement of the initial rate of glucose transport using $[1-3 \mathrm{H}]$ glucose. We used the method described earlier (Loureiro-Días \& Peinado, 1984), with some modifications. We suspended $1 \mathrm{mg}$ (dry weight) of cells in $40 \mu 150 \mathrm{~mm}$ Tris/citrate buffer in a conical tube incubated in a water bath at $28^{\circ} \mathrm{C}$. After 2 min incubation, $10 \mu$ of a solution of the labelled sugar (specific activity about $10 \mathrm{GBq} \mathrm{mol}^{-1}$ ) were added. Transport was stopped $10 \mathrm{~s}$ later by the addition of $5 \mathrm{ml}$ ice-cold water. Cells were filtered under vacuum through Whatman GF/C membranes, washed with $5 \mathrm{ml}$ ice-cold water, and radioactivity was measured in a liquid scintillation system.

To study the kinetics of the high-affinity system we used only $0.1 \mathrm{mg}$ of cells and a specific activity ten times higher; otherwise, due to the low glucose concentrations used, the sugar was significantly consumed during the assay. In some experiments we measured the capacity of this system as the initial rate of transport for a concentration of $0.1 \mathrm{mM}$-glucose, since at this concentration the high-affinity system was saturated and the transport through the low-affinity one(s) was not significant. To study the kinetics of the low-affinity facilitated diffusion, we varied the concentration of glucose between 0.125 and $500 \mathrm{~mm}$. This was accomplished by adding a fixed amount of labelled sugar ( $0 \cdot 1 \mathrm{MBq})$ to all the assays and varying the specific activity with concentration. In all cases we checked that $10 \mathrm{~s}$ was within the time interval during which the uptake of radioactive glucose was linear with time.

Measurement of the initial rate of glucose transport by $\mathrm{H}^{+}$uptake. We used the method previously described (Loureiro-Días \& Peinado, 1984) with suitable concentrations of glucose.

Measurement of accumulation ratios. Accumulation ratios were calculated for $\mathrm{L}-\left[\mathrm{U}-{ }^{14} \mathrm{C}\right]$ sorbose, as already described (Loureiro-Días, 1987). In previous experiments, mutual competitive inhibition of transport of $L$-sorbose and glucose was observed in this strain.

Maltose consumption capacity. Maltose consumption capacity in chemostat-grown cells was evaluated by the ability of cell suspensions to acidify the unbuffered external environment upon addition of maltose (10 mM initial concentration). The same conditions were used as those utilized to measure initial $\mathrm{H}^{+}$uptake. Relative values were calculated taking as $100 \%$ the value obtained with cells grown in the chemostat at the lowest dilution rate (derepressed cells).

Determination of sugars. Glucose was determined by the oxidase-peroxidase method (Boehringer Mannheim). Total sugars (glucose plus maltose) were determined by the phenol/sulphuric acid method (Herbert et al., 1971). Maltose was taken as the difference between the two values.

\section{RESULTS}

\section{Kinetics of growth and glucose consumption in chemostat-grown cells}

Candida utilis IGC3092 was grown in the chemostat on a mixture of glucose $\left(3 \mathrm{~g}^{-1}\right)$ and maltose $\left(1 \mathrm{~g} \mathrm{l}^{-1}\right)$, at several dilution rates, as described in Methods. The steady-state values of biomass and sugar concentrations at each dilution rate were determined (Fig. 1). Maltose consumption was used as an indicator of glucose repression, in an attempt to check if the same repression mechanisms acting on maltose consumption would act on some of the transport systems for glucose. We had previously shown (Peinado et al., 1987) that glucose represses maltose consumption in the chemostat, so the maltose consumption capacity of the cells was determined to verify the conditions at which glucose repression was triggered. Fig. 1 shows that this happened at a dilution rate of $0.25 \mathrm{~h}^{-1}$, corresponding to a glucose concentration of $0.7 \mathrm{mM}$. Increasing the dilution rate led to decrease in maltose consumption capacity and, correspondingly, the maltose concentration in the fermenter increased. When the concentration of glucose reached $9.6 \mathrm{mM}$, repression was complete and the maltose concentration in the fermenter was that of the fresh medium.

When the kinetics of growth was studied, we found that the dependence of specific growth rate on the external glucose concentration did not follow the Monod equation. Instead, a non- 


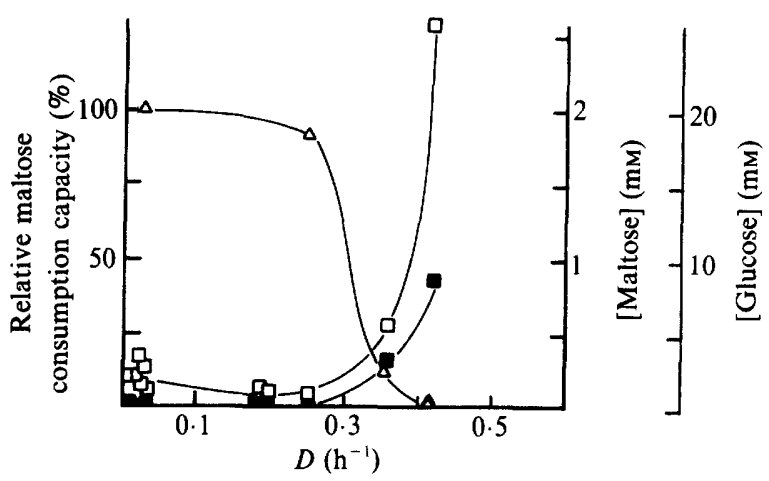

Fig. 1

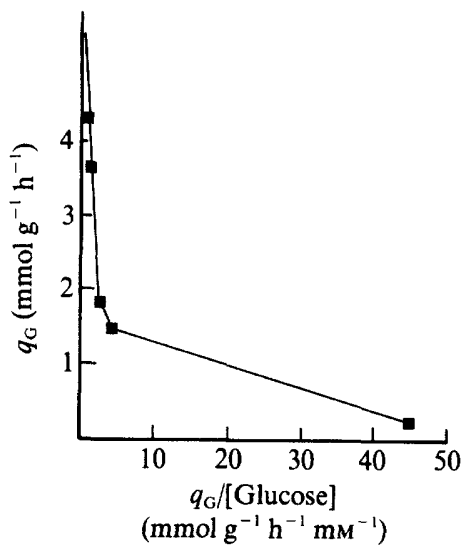

Fig. 2

Fig. 1. Steady-state concentrations of glucose $(\square)$ and maltose $(\square)$ in the chemostat, and relative maltose consumption capacity $(\triangle)$ of $C$. utilis at several dilution rates $(D)$.

Fig. 2. Eadie-Hofstee plot of the specific glucose consumption rate, $q_{\mathrm{G}}$, of $C$. utilis and the steady-state glucose concentration in the chemostat.

linear Eadie-Hofstee plot was obtained. From this non-linear plot (not shown) a maximum specific growth rate of $0.47 \mathrm{~h}^{-1}$ was extrapolated from the higher $D$ values and apparent affinities for glucose $\left(K_{\mathrm{s}}\right)$ of about 0.83 and $0.03 \mathrm{~mm}$ were calculated from the higher and lower $D$ values respectively. As this was a carbon-limited culture, similar changes in the apparent affinity for glucose of the specific rate of glucose consumption were to be expected, and they were indeed observed. Fig. 2 shows an Eadie-Hofstee plot of the specific consumption rate of glucose versus the corresponding glucose concentration in the fermenter. From these data, a maximum rate of glucose consumption of $4.9 \mathrm{mmol} \mathrm{g}^{-1} \mathrm{~h}^{-1}$ and apparent $K_{\mathrm{m}}$ values of about $1 \cdot 1$ and $0.03 \mathrm{~mm}$ were calculated. These results showed that the apparent affinity for glucose uptake depended on the concentration of the sugars at which the cells were growing. The changes in apparent affinity could correspond to changes in the transport system utilized by the yeast, so we tried to characterize and identify these potentially different systems.

\section{Simultaneous presence of a $\mathrm{H}^{+}$symport and a facilitated diffusion system for glucose transport in chemostat grown cells.}

The initial transport rate of glucose was assayed in washed cells that had grown in the chemostat at a dilution rate of $0.2 \mathrm{~h}^{-1}$ with a glucose concentration of $0.3 \mathrm{~mm}$.

When transport was measured with radioactive glucose (see Methods), the Eadie-Hofstee plot of the initial velocities against the concentration of glucose was biphasic (Fig. 3), indicating the presence of at least two transport modes with affinities around $20 \mathrm{mM}$ and $20 \mu \mathrm{M}$. To determine whether the high-affinity form was a $\mathrm{H}^{+}$symport that had been previously described for $C$. utilis (Eddy \& Hopkins, 1985), the initial transport rate was measured by following $\mathrm{H}^{+}$ uptake by a cell suspension after glucose addition, as described in Methods. The Eadie-Hofstee plot of $\mathrm{H}^{+}$uptake, also shown in Fig. 3, was linear, showing an affinity and capacity similar to those of the high-affinity component detected previously by the radioactive glucose method. We concluded that the high-affinity form was a $\mathrm{H}^{+}$symport with a stoichiometry of one mole of glucose per proton cotransported, as Eddy \& Hopkins (1985) had found for cells grown with lactate or low concentrations of glucose. This symport could be used also by sorbose, as competition experiments showed.

To distinguish further between the two forms of transport, their ability to accumulate sorbose was investigated. The symport was studied in cells grown in the chemostat at low dilution rate, and the low-affinity system in cells grown in batch culture with $2 \%(w / v)$ glucose (in these batch- 


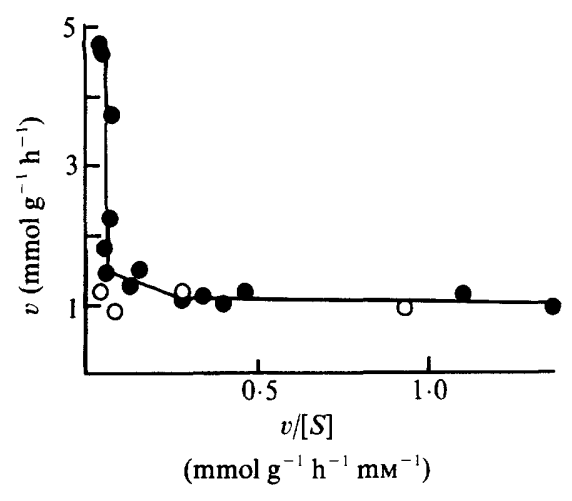

Fig. 3

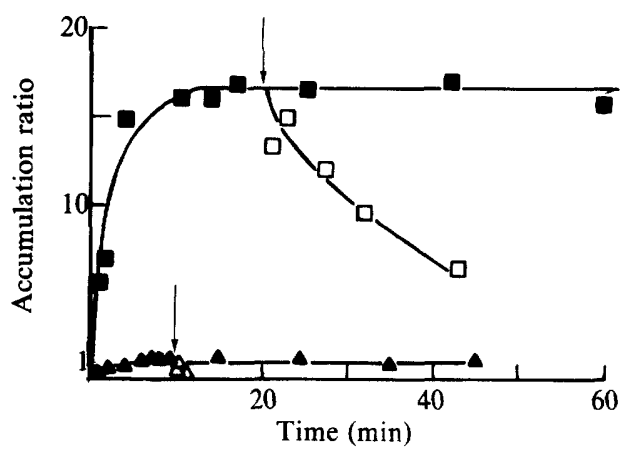

Fig. 4

Fig. 3. Eadie-Hofstee plot of the initial rate of glucose transport by cells of $C$. utilis previously grown in the chemostat at a dilution rate of $0 \cdot 2 \mathrm{~h}^{-1}$. The transport was measured by following $\left[{ }^{3} \mathrm{H}\right]$ glucose incorporation (O) or $\mathrm{H}^{+}$uptake $(\mathrm{O})$.

Fig. 4. Accumulation of $\mathrm{L}-\left[\mathrm{U}-{ }^{14} \mathrm{C}\right]$ sorbose by $C$. utilis cells grown under derepression conditions (low dilution rate in the chemostat) $(\square, \square)$ and repression conditions $(2 \%, w / v$, glucose batch culture $)(\boldsymbol{A}$, $\triangle$ ). Open symbols follow the addition of $1 \mathrm{~mm}$-glucose.

grown cells no $\mathrm{H}^{+}$uptake was observed upon addition of glucose). As expected, the symport accumulated the non-metabolizable analogue up to 15-fold, and addition of glucose produced counterflow (Fig. 4). In contrast, the low-affinity transport system of batch-grown cells was equilibrative: i.e. it was a facilitated diffusion.

These experiments showed that the cells could display two clearly distinct transport systems: a $\mathrm{H}^{+}$symport and a facilitated diffusion. Apparently, both systems could be present simultaneously in chemostat-grown cells (see Fig. 3). We will henceforth refer to the highaffinity system as the $\mathrm{H}^{+}$symport and to the low-affinity system as the facilitated diffusion.

\section{Regulation of the glucose- $\mathrm{H}^{+}$symport}

The glucose- $\mathrm{H}^{+}$symport was also found in cells grown in batch culture on lactate, as described by Eddy \& Hopkins (1985), and on other gluconeogenic carbon sources such as ethanol and glycerol, but not on glucose. The results, summarized in Table 1, showed that the symport was partially constitutive and repressed by glucose. Moreover, the symport could be found in cells previously grown under repressing conditions ( $2 \%$ glucose), after $4 \mathrm{~h}$ starvation in buffer. This process was inhibited by the presence of cycloheximide in the starvation buffer, indicating that derepression required de novo protein synthesis (Table 1). When cells grown in the chemostat at different growth rates were analysed for their capacity to transport glucose with high affinity, measuring both the incorporation of radioactive glucose and the uptake of $\mathrm{H}^{+}$, the results confirmed the stoichiometry $1: 1(1 \cdot 08 \pm 0 \cdot 27, n=8)$, and also showed that the symport was induced by glucose. As shown in Fig. 5, cells grown in the chemostat at the lowest glucose concentration studied had a symport capacity similar to the basal level detected in ethanolgrown cells (see Table 1). When the cells were grown at higher glucose concentrations their symport capacity increased, reaching a value three times the basal level at a glucose concentration of $0.7 \mathrm{mM}$, which corresponded to a dilution rate of $0.25 \mathrm{~h}^{-1}$. Beyond this dilution rate, i.e. at higher glucose concentrations, repression was triggered, and at a glucose concentration of about $10 \mathrm{mM}$ repression was complete, as happened with the maltose consumption capacity (see Fig. 1). Comparing Fig. 5 and Fig. 1 it can be concluded that both systems, the glucose- $\mathrm{H}^{+}$symport and the maltose consumption capacity, show the same glucose dependence in their repression, indicating a common underlying control mechanism. 


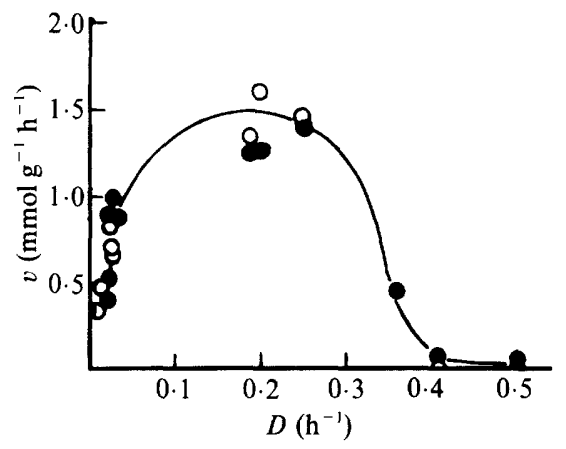

Fig. 5. Glucose- $\mathrm{H}^{+}$symport capacity of $C$. utilis cells grown at several dilution rates $(D)$ in the chemostat. The transport capacity was measured either by following $\mathrm{H}^{+}$uptake upon the addition of $10 \mathrm{~mm}$-glucose (O), or with $0 \cdot 1 \mathrm{mM}-\left[{ }^{3} \mathrm{H}\right] \mathrm{glucose}(\mathrm{O})$.

Table 1. Uptake of glucose by the high-affinity system $\left(\mathrm{H}^{+}\right.$symport) in $\mathrm{C}$. utilis cells grown in batch culture on different substrates

$\left[1-{ }^{3} \mathrm{H}\right]$ Glucose incorporation was measured after $10 \mathrm{~s}$ incubation with saturating $(0 \cdot 1 \mathrm{~mm})$ glucose.

Results are mean values of at least two experiments.

$\begin{array}{lc}\text { Growth substrate } & \begin{array}{c}\text { Uptake } \\ \left(\mathrm{mmol} \mathrm{g}^{-1} \mathbf{h}^{-1}\right)\end{array} \\ \text { Lactate } & 0.58 \\ \text { Ethanol } & 0.40 \\ \text { Glycerol } & 0.20 \\ \text { Glucose }(2 \%, \text { w/v) } & \\ \quad \text { Exponential-phase cells } & 0.07 \\ \text { Exponential-phase cells } & \\ \quad \text { after 4 h starvation } & \\ \quad \text { Without cycloheximide } & 0.30 \\ \quad \text { With cycloheximide } & 0.04\end{array}$

\section{Features of the facilitated diffusion for glucose}

Even the cells that had grown in the chemostat at the lowest glucose concentration (below $10 \mu \mathrm{M})$, showed a biphasic Eadie-Hofstee plot, with a low-affinity component, as that of Fig. 3, when assayed for their initial transport capacity with glucose concentrations up to $100 \mathrm{~mm}$. This means that the facilitated diffusion system was present. Although the capacity could not be determined precisely from these plots, the values obtained for the set of dilution rates studied (those of Fig. 5) were of the same order as the maximum rate of glucose uptake by batch-grown cells: about $5 \mathrm{mmol} \mathrm{g}^{-1} \mathrm{~h}^{-1}$. We concluded that the synthesis of the facilitated diffusion system does not seem to depend on the concentration of glucose.

The kinetics of the facilitated diffusion system was studied using mainly batch grown cells, in which only this system was present. Eadie-Hofstee plots of the initial velocities using glucose concentration up to $0.5 \mathrm{M}$ were biphasic. Fig. 6 shows the results of a typical experiment. This non-linear behaviour could be explained by two different mechanisms: either there are two distinct permeases able to transport glucose by facilitated diffusion or there is a single permease whose affinity depends on the glucose concentration. In the case of the first possibility, $K_{\mathrm{m}}$ values of $2 \mathrm{mM}$ and $1 \mathrm{M}$ could be calculated for each permease, separating the values for initial glucose transport through each system from the experimental results, by iterative procedures. The second possibility could be further explored theoretically. Extrapolating the maximum velocity from Eadie-Hofstee plots such as that of Fig. 6, a Hill plot was prepared. Fig. 7 shows such a plot for the same data as those of Fig. 6. The system seemed to behave as a single permease that could be in two different states: at low glucose concentrations (below $7 \mathrm{~mm}$ ) all the 


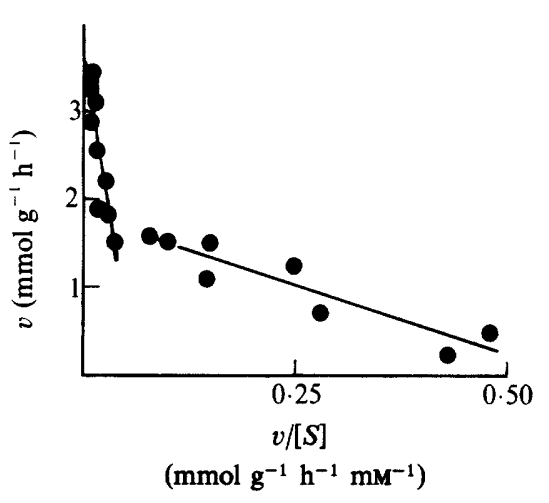

Fig. 6

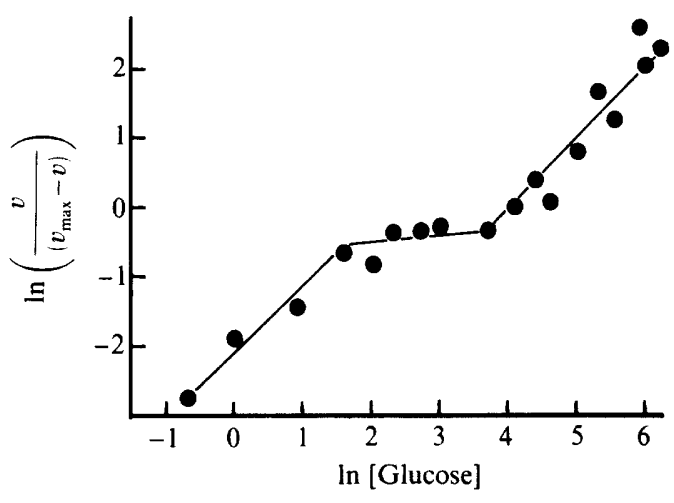

Fig. 7

Fig. 6. Eadie-Hofstee plot of the initial rate of transport of $\left[{ }^{3} \mathrm{H}\right]$ glucose by $C$. utilis cells grown in batch culture with $2 \%(\mathrm{w} / \mathrm{v})$ glucose.

Fig. 7. Hill plot of the initial rate of transport of $\left[{ }^{3} \mathrm{H}\right]$ glucose by $C$. utilis cells grown in batch culture with $2 \%(\mathrm{w} / \mathrm{v})$ glucose. The data are the same as those of Fig. $6 ; v_{\max }$ was extrapolated from the upper part of that curve.

Table 2. Hill coefficients and apparent affinities of the glucose facilitated diffusion system of C. utilis cells grown in batch culture with $2 \%(w / v)$ glucose

The mean and standard deviation of three independent experiments are given. Initial transport rate was measured with $\left[{ }^{3} \mathrm{H}\right]$ glucose, varying the sugar concentration between 0.125 and $500 \mathrm{~mm}$. Hill and Eadie-Hofstee equations were applied to calculate the parameters.

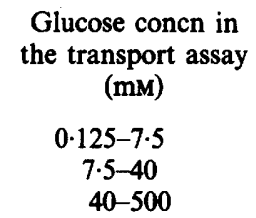

$\begin{array}{cc}\begin{array}{c}\text { Hill } \\ \text { coefficient }\end{array} & \begin{array}{c}\text { Apparent } \\ \text { affinity } \\ (\mathrm{mM})\end{array} \\ 0.9 \pm 0.03 & 2 \cdot 0 \pm 1 \cdot 2 \\ 0.3 \pm 0.07 & - \\ 1.0 \pm 0.02 & 76 \pm 40\end{array}$

permease would be in the higher-affinity state, whereas at concentrations higher than $40 \mathrm{~mm}$ all would be in the low-affinity state. At intermediate concentrations a mixture of states would coexist. Table 2 summarizes the conditions and kinetic parameters of both states.

\section{DISCUSSION}

Candida utilis grown in chemostat and batch culture displays a set of transport systems for glucose in what seems to be a general pattern among several yeasts: Candida wickerhamii (Spencer-Martins \& van Uden, 1985), Candida sheatae (Lucas \& van Uden, 1986), Candida intermedia (Loureiro-Días, 1987), Pichia ohmeri (Verma et al., 1987) and Kluyveromyces marxianus (Gasnier, 1987). In all these yeasts two systems were found: $\mathrm{a}^{+}$symport when there is no, or a very low concentration of, glucose in the growth medium, and a facilitated diffusion system in the presence of higher concentrations of the sugar.

In $C$. utilis, we found a $\mathrm{H}^{+}$symport displaying simple hyperbolic kinetics and a facilitated diffusion with a complex behaviour. Both systems could be observed simultaneously in chemostat-grown cells at steady-state glucose concentrations below $10 \mathrm{mM}$ (Fig. 3), although the relative contribution of each system to the total flow of sugar depended on the sugar concentration. 
The $\mathrm{H}^{+}$symport has such a high affinity $\left(K_{\mathrm{m}}\right.$ about $\left.15 \mu \mathrm{M}\right)$ that it is saturated under any conditions where glucose can be detected, so it makes sense that its regulation has to be based on the amount of carrier present in the cells (Fig. 5), controlled by induction and repression. It is also conceivable that the $\mathrm{H}^{+}$symport may be inactivated by glucose or even interconverted into a facilitated diffusion system, as previously described in other yeasts (Spencer-Martins \& van Uden, 1985; Verma et al., 1987). In contrast, according to our results, regulation of transport at high glucose concentrations might be achieved by changes in the affinity of a single carrier (Fig. 7), although the possibility that two systems might be present should not be discarded.

In Saccharomyces cerevisiae, biphasic Eadie-Hofstee plots for initial transport of glucose have also been described (Bisson \& Fraenkel, 1984; Busturia \& Lagunas, 1986). High-affinity facilitated diffusion has been shown to depend on the presence of some of the glucosephosphorylating enzymes of this yeast. Current work in one of our laboratories is trying to identify these types of enzyme in C. utilis, looking also for kinase-negative mutants. On the other hand, the existence of low-affinity facilitated diffusion in yeasts needs to be re-evaluated, measuring transport at higher concentrations of glucose than those usually used.

If there is a single carrier for facilitated diffusion in C. utilis, it remains to be elucidated if its changes in affinity are due to allosteric mechanisms involving a complex permease with several subunits, or to hysteretic behaviour of a monomeric permease. The allosteric mechanism was suggested some years ago (Barnett \& Sims, 1976), based on kinetic experiments. The isolation of the permease(s) and/or the corresponding gene(s) seems the only way to solve this problem.

We thank Professor N. van Uden, of the Gulbenkian Institute of Science, for helpful discussions.

This work was supported in part by a grant from the Comision Interministerial de Ciencia y Tecnologia (CICYT, Spain), proyect BT20/86.

\section{REFERENCES}

BarnetT, J. R. \& Sims, A. P. (1976). A note on the kinetics of uptake of D-glucose by the food yeast, Candida utilis. Archives of Microbiology 111, 193194.

Bisson, L. F. \& FraENKel, D. G. (1984). Expression of kinase-dependent glucose uptake in Saccharomyces cerevisiae. Journal of Bacteriology 159, 1013-1017.

Busturia, A. \& Lagunas, R. (1986). Catabolite inactivation of the glucose transport system in Saccharomyces cerevisiae. Journal of General Microbiology 132, 379-385.

EDDY, A. A. (1982). Mechanisms of solute transport in selected eukaryotic microorganisms. Advances in Microbial Physiology 24, 1-79.

EDDY, A. A. \& HopkINS, P. G. (1985). The putative electrogenic nitrate-proton symport of the yeast Candida utilis. Biochemical Journal 231, 291-297.

GASNIER, B. (1987). Characterization of low- and highaffinity glucose transports in the yeast Kluyveromyces marxianus. Biochimica et biophysica acta $\mathbf{9 0 3}$, 425-433.

Herbert, D., Phipps, P. J. \& Strange, R. E. (1971). Chemical analysis of microbial cells. Methods in Microbiology 5B, 210-344.

HOFER, M. \& MisRA, P. C. (1978). Evidence for a proton-sugar symport in the yeast Rhodotorula gracilis (glutinis). Biochemical Journal 172, 15-22.

Loureiro-Dias, M. C. (1987). Glucose and polyol transport systems in Candida intermedia and their regulation. Journal of General Microbiology 133, 2737-2742.
Loureiro-Dias, M. C. \& Peinado, J. M. (1984). Transport of maltose in Saccharomyces cerevisiae. Effect of $\mathrm{pH}$ and potassium ions. Biochemical Journal 222, 293-298.

LuCAS, C. \& VAN UDEN, N. (1986). Transport of hemicellulose monomers in the xylose fermenting yeast Candida sheatae 23. Applied Microbiology and Biotechnology 23, 491-495.

Peinado, J. M., Barbero, A. \& Van Uden, N. (1987). Repression and inactivation by glucose of the maltose transport system of Candida utilis. Applied Microbiology and Biotechnology 26, 154-157.

Postma, E., van DiJken, J. P. \& Scheffers, W. A. (1987). Kinetics of glucose uptake in carbon limited chemostat cultures of Candida utilis. In Proceedings of the 4th European Congress on Biotechnology, vol. 3, p. 368. Edited by O. M. Neijssel, R. R. van der Meer, \& K. Ch. A. M. Luyben. Amsterdam: Elsevier.

SPENCER-MARTINS, I. \& VAN UDEN, N. (1985). Catabolite interconversion of glucose transport systems in the yeast Candida wickerhamii. Biochimica et biophysica acta 812, 168-172.

VAN UDEN, N. (1967). Transport-limited fermentation and growth of Saccharomyces cerevisiae and its competitive inhibition. Archives of Microbiology 58, 155-168.

Verma, R. S., SPEnCer-Martins, I. \& VAN Uden, N. (1987). Role of de novo protein synthesis in the interconversion of glucose transport systems in the yeast Pichia ohmeri. Biochimica et biophysica acta $\mathbf{9 0 0}$, 139-144. 